\title{
CHARACTERISTICS OF SOCIO-ALIVE BUILDING: THE CASE OF BAHRAIN CITY CENTER
}

\author{
Ashraf M. SOLIMAN ${ }^{1, *}$, Ali M. ALKHALEFA ${ }^{2}$ \\ ${ }^{1}$ Department of Architectural Engineering, Faculty of Engineering, Minia University, Mina Egypt and College of \\ Architecture Engineering and Design, Kingdom University, Bahrain \\ ${ }^{2}$ Town Planner at Ministry of Housing, Kingdom, Bahrain
}

Received 04 May; accepted 21 November 2017

\begin{abstract}
Socio-Alive Building is Architecture where people enjoy being around to live within its environment and want to come back after leaving. This paper discusses the terminology of Socio-Alive Building and identifies the building characteristics which make a building social and alive. The main aim of this paper is to discuss the concept of alive-socio building as an approach to keep the building alive and have social role through the consideration of characteristics of socio-alive building. The paper begins by introducing the definitions of Socio-Alive Building and then discusses the characteristics of Socio-Alive Building to construct a theoretical background, then reports the outcomes of a survey in Bahrain to find out perceptions of people of Bahrain toward building characteristics, which could produce socio-alive build environments. A people's survey concluded significance scale factors of building characteristics that achieve the sociality and alive of the building in Bahrain which were used to evaluate Bahrain City Center. The paper offers ten compromised building characteristics that can produce Socio-Alive with certain significance scale of each. The authors argue that these could be considered during design process to produce socio-alive buildings.
\end{abstract}

Keywords: alive architecture, Socio-Alive Building, Building characteristics, public space, form, Bahrain urbanization.

\section{Introduction}

Socio-Alive Building is an outcome of a process of using scientific and mathematical tools to develop organic designs incorporating natural elements like greenery, water, light and shadows to make design flexible and live turning built-environment friendlier and hospitable. Socio-Alive Building is psychologically comforting and physically allows buildings to grow (flexibility) according to the needs of a family. Architecture is in fact an art form, which gives expression to concrete lifeless buildings, whereby people start relating to the structures as home, work place, place of social gathering, recreation etc. The building should not only relate to the need and function of the structure but also make the user physically and psychologically secure and comfortable. Socio-Alive Building is all about this objective. It is a design which combines scientific and mathematical designs with live elements like space, light and shade, water, greenery psychologically based colors, forms and shapes, and building materials to create harmonious products that can positively affect the people and improve their quality of life. Use of Live (natural) elements like water, which is a symbol of life, greenery that is life itself is crucial for the apparent impact while cooler building materials, space management, light and shadows will be crucial for abstract influences; the interplay of these elements is equally important for indoor and outdoor compositions. People like to be surrounded by living things that make them more comfortable. Building materials can be made live by adding more living things like plants and water which will gather other forms of life, birds, butterflies etc. ..., making it a great place to live in. Socio-Alive Building is an interplay of a variety of elements such as water, plants (greenery) etc, in public or social buildings. It can cast a very soothing impact on users and can make them more creative and thereby enhance creativity. Similarly, direct light and shade can be used to enhance aesthetics and make buildings healthier and environmentally friendly. Architecture nowadays is much more than fulfillment of physical and social needs in a mechanical manner. The main aim of this paper is to discuss the concept of alive-socio building as an approach to keep the building alive and have social role. That aim

${ }^{*}$ Corresponding author. E-mail: arcgroupfec@yahoo.com 
might be achieved with providing examination criteria of alive-socio building through compromised building characteristics. This paper follows three research methodologies. The first is a theoretical method which investigates literature and background of ten characteristics of SocioAlive Building which are space, proportions, greenery, live color, natural lights, flexibility, shape, water feature, multifunction, ornaments and patterns. The result of that review has been reflected on following methods. The second is an empirical method conducted with a survey of users evaluating those characteristics to find out the impact factor of each characteristic of alive architecture. The third is an analytical method in which a case study has been analyzed based on the characteristics of alive architecture.

\section{Literature review}

Alive-socio concept of designing a public building has a new approach to design challenges, which integrates the concepts of social, environmental and alive approaches. Therefore the authors focus on reviewing different relative design concepts such as social building, living building and alive architecture.

Social architecture is a comprehensive design of a built- environment that enthuses the intended social behaviors, the development partners' approach which involve the end-users to participate in making decision in the design process is a social concept. The participation of residents in design process and emphasized the important of understanding the needs and behavior of the new generation users to meet their social needs (AlYaqoobi, 2013). Al-Yaqoobi also recommended characteristics of buildings within social neighborhood are closed, mix uses, close entrance, include playground and close to mosque, school and hospital. The social architecture is not to control people, it is a method used to encourage good behavior and maximize the human interactions and productively (Gatsby, 2014).

Living building is a team used for green building certification with sustainable design approach, the certified living building shall be regenerative spaces, energy Selfsufficient, healthy and beautiful. The living building shall connect residents to light, air, food, nature, and community. It shall be not only alive within a limited resource of its site but also produce energy more than its needs (Living building basics, 2017). There are seven aspects shall be designed with sustainability considerations in order to certify the building as a living building; sport lifestyle of the site, reuse the water, self-producing energy, promoting users' health, green listed materials, provide equity for all workstations in teams of fresh air and natural lights and beauty of the building by innovative design even for technical installments arrangement, green roof, etc.

According to alive architecture website; Alive architecture initiated in Brussels focuses on the public spaces in the City rather than the built spaces that architects usually deal with. Location values and identity are enhanced by visible and invisible (perceiving, experiencing, socializing, and transforming) space. Alive architecture encourage lived space in public spaces in the city by implementing the results of the studies on site mappings, transitional workshops and co-constructional of the built space. The team of alive architecture network have design strategies for urban transformation process considering history of the site, and spatial, social and economic transformation situation. The goal of these strategies is to create comprehensive with unique identity neighborhoods where the local is allowed to welcome their guests. Thus, alive architecture is to make the daily users appreciate space (Pferdmenges, 2017). In the context of the social, living and alive architecture the authors identify Alive-socio building as the building that compromises most of the sustainability and sociality challenges to be alive by its sustainable features and attracting people by its design characteristics as well.

\section{Characteristics of alive architecture}

\subsection{Space}

In this paper, space is the public space, where public has wide and rich meaning to people because it is accessible to everybody in the society (Ercan, 2010). Everyday activities such as trading, gathering, communicating, relaxing and resting usually happens in the public spaces. Public space can also cater to psychological or purely physical needs, which affects human behavior (Shaftoe, 2008). This concept interprets the demand of characteristic of liveness to the space. However, in everyday life, space is understood simply as emptiness, or the absence of things or nothingness. Our world consists of 'things' \& 'no things', empty space, empty area or empty volume. In architecture, it is more complex. Space is always experienced and referred to as a nice space or the opposite in terms of quality; spatiality of space away from space as emptiness. However, both these understandings are employed in creating art in architecture. Identity of space influences user behavior and activates within the space. Therefore, every space should have its own identity which comes from multiple axial aspects such as the location, belonging, concepts behind it, attachments to Nature and sustainable forms (Proshansky, Fabian, \& Kaminoff, 2014). Space exists everywhere and in architecture, a small portion of space is taken sculptured and transformed to another space to serve a certain need or function. This new space created can be enclosed or open, and this is how architecture is created. A building is a series of spaces attached and related to each other. Architecture is gathering spaces the same way poetry gathers words in harmony to create spaces that gives powerful emotions. These spaces must be other than everyday spaces, i.e.; sculptured space in poetic way to create emotional and enjoyable spaces with poetic quality. A space is a physical location having length, width, scale, geometry, texture, color, light and can change through time. Space has codes, rules, and abstract parts shaping meaningful things in space. To understand space, the key element is to relate this space to human dimensions and to convert this space from its natural form to its usable and 
consumable form. Space is the media of architecture. Architectural design of space is to provide the occupants with their different needs (functional, social, representational, cultural, aesthetic and emotional) etc. Architects usually concentrate on fulfilling the functional needs like climate, natural lighting, privacy, social, and ecological needs etc. Architects need to imagine the space and think about other spaces around by understanding its nature and built forms. In this way, architects can start designing spaces based on their concepts and principles according to their understandings (Koch, Marcus, \& Steen, 2009) Spatial knowledge stemming from experience which acts as a network interwoven between interrelated concepts such as body, scale, proportion, experience, perception, atmosphere, senses, time, memory, context, light, structure, materials, architectonics, spatial articulation and syntax (Kurtuncu, Koknar, \& Dursun, 2008). 'Space is a social product' (Lefebvre, 1999). He said that space is modified, supported and produced by social relations. Inner courtyard space could combine a public and private space characteristic which also provides the life to the building. TV house in Belgium is one of the successful single family houses with its semi private open space as shown Figure 1.

\subsection{Design proportions}

Richard Radovan mentioned that although architectural proportion is an artificial and abstract mathematical ordering which describes mathematical properties of the natural objects especially the human body, the Nature's proportions cannot be grasped for function but would be important to art and aesthetics (Padovan, 2009). Design of living things in Nature has an accurate numerical and structural order. It is well designed, mathematically and geometrically proportioned invisible design, which will be clearly understood only when it is closely studied. The beauty of a flower is felt yet its secret isn't understood until it is carefully studied. Flowers, sea shells, the pyramids of Egypt, the Parthenon,

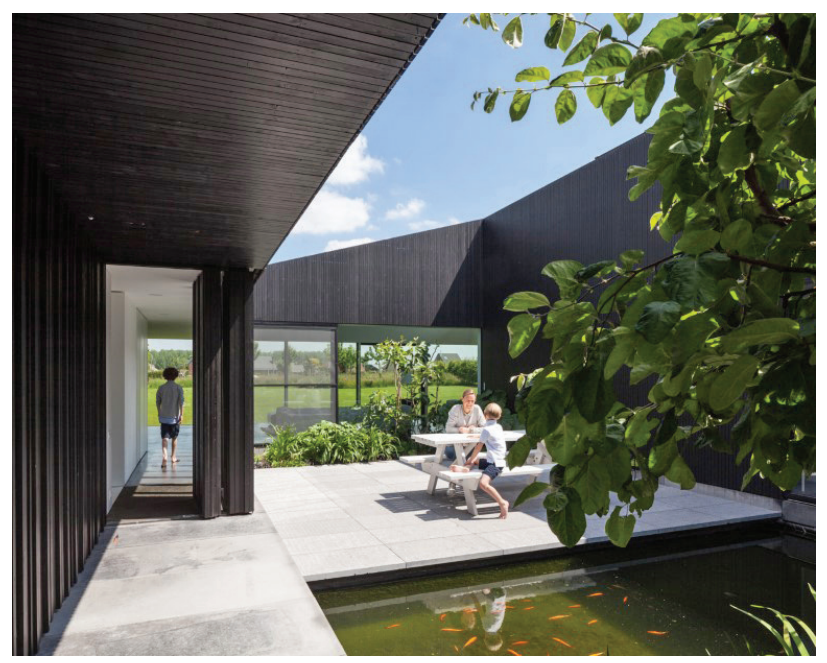

Figure 1. TV House, Belgium (source: TV House is made Up by different volumes centered around a green space by Bruno Vanbesien architects, 2016) all have one thing in common and that is the number 1.618 or the Golden Section. The golden section is a mysterious number; 1.618 also called Phi, which has many interesting properties that are found in many living things. Shapes and designs based on the golden section have been considered aesthetically pleasing for thousands of years. It is also found in Nature and has been used as a base for designing important and monumental buildings through time. Taj Mahal has one of the most successful proportions that makes the building alive because all its parts of façade's composition are designed to have a golden ratio.

\subsection{Greenery}

Greenery is the main characteristic of ecological buildings which provide social and economic benefits for the developers in the aspects of reducing life-cycle costs, developing functional performance, encouraging social relationships at buildings communities and enhancing building images (Edwards, 2013). Green has now became an essential design consideration around the world especially for addressing and facing the threats of climate change (Kenneth \& Tammy, 2017). Dover points out that green is not only for outside of buildings. He allocated a chapter in Green Infrastructure book to illustrate the value of combining greenery inside a building. These include aspects such as reducing noise, contributing to the therapeutic process by visual access to greenery, conditioning the air by producing acceptable ranges of humidity $(30-70 \%)$ and temperature $\left(20-24{ }^{\circ} \mathrm{C}\right)$, reducing the probability of Bacteria's growth by $50 \%$, mitigating air pollution by reducing greenhouse gas elaboration levels. Moreover, many mechanisms remove volatile organic carbon based compounds from the air which have the ability to vaporize at normal room temperatures (Dover, 2015). Greenery is essential for Socio-Alive Building which is all about the life of the people and the improvement of the relations between built and living environments. This cannot be achieved without the existence of natural materials like greenery. Green trees and plants are live elements that give life to the built areas. Great views attract different kinds of living beings like birds, butterflies, a natural theme for making it more suitable for human life and enjoyment. It also has a lot of benefits to human health.

- Experience of Nature helps to restore the mind from the mental fatigue of work or studies, contributing to improved work performance and satisfaction.

- Urban Nature, when provided as parks and walkways and incorporated into building design provides calming and inspiring environments and encourages learning, inquisitiveness, and alertness.

- Green spaces provide necessary places and opportunities for physical activity. Exercise improves cognitive function, learning, and memory.

- Contact with Nature helps children to develop cognitive, emotional, and behavioral connections to their nearby social and biophysical environments. Nature experiences are important for encouraging imagination and creativity, cognitive and intellectual development, 
and social relationships. White Walls residential of the tower designed by Paris-based Ateliers Jean Nouvel and located in Nicosia, Cyprus is an example of the most successful alive building achieved by greenery as sown in Figure 2. the building structure is integrated with greenery like hanging gardens of Babylon.

\subsection{Live colors}

Color is a major part of life. Everything around us has its own properties defining it, including its color. Color is a powerful element in Architecture. Architects need to understand the power of colors and the long term effects on people using a space. Architects must know how to choose colors to create certain emotions and feelings for the correct function of a space. For example, some colors are chosen to give the impression of greeting, comfort, royalty, and celebration etc. Different building materials have different colors like; limestone, stucco, terra cotta, stone, bricks, concrete, painted concrete, wood, steel, aluminum, and glass etc. Color is related to human emotions and behavior. We spend most of our lives inside and around buildings. Every space shall have its own set of colors, carefully selected depending on its function or activity taking place and according to scientifically proven tests. This is for providing the occupants the right messages and the right feelings, mood etc., either directly or indirectly. According to studies related to psychology of architecture (Lehrer, 2011), the influence of color on human imagination was the focus of the study. Six hundred persons performed a variety of basic cognitive tests in rooms with red, blue and neutral colored walls. The experiment showed that the test rooms with the red walls influenced people's skills in accuracy and attention to details.

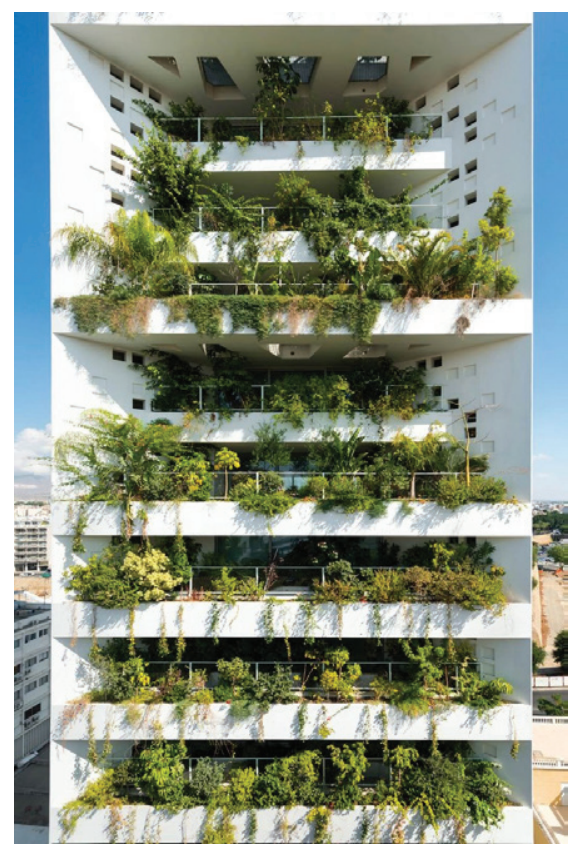

Figure 2. White Walls residential tower, Nicosia, Cyprus (source: Photo by Yiorgis Yerolymbos, 2016)
For example, it affected finding spelling mistakes or keeping random numbers in short-term memory according to scientists. This is because people relate red with danger, making them more awake and alert. While people in the test room with the blue colored walls were worse on shortterm memory tasks, they were much better on creativity. This is because blue reminds us of the sky and ocean, allowing us to easily daydream and imagine deeply away from reality (Lehrer, 2011). Ohio State University and the National Institute of Mental Health studied sixty workers and a group of them were allowed to work at an old office building with noisy air conditioners and low ceilings, while the rest of the group were allowed to work in a renovated building with skylights and open cubicles. In around 17 months of study, the scientists were observing emotional well-being using a metric scale such as heart rate, levels of stress hormone, etc. The scientists found that the workers in old buildings were more stressed even when they weren't at work and said that the effects were enough to cause heart disease through time. Emily Anthes mentioned that in 2007, Joan Meyers-Levy said that when the room ceiling is high, people tend to see the relation between seemingly unrelated subjects. One of the experiments showed that undergraduates came up with $25 \%$ more connections between different sports like chess and basketball when sitting in loft like space than in a room with an 8 foot ceiling (Anthes, 2009).

According to a recent study, females are more sensitive to color and have higher range of color taste. The color red causes increase in the release of adrenalin, heart rate, and gastric activity. This is why many restaurants use the color red for their tables and cloths. The gray color room causes increase in heart rate more than colorful rooms (Ronchi, 2015) as shown in Figure 3. Family housing in Barcelona

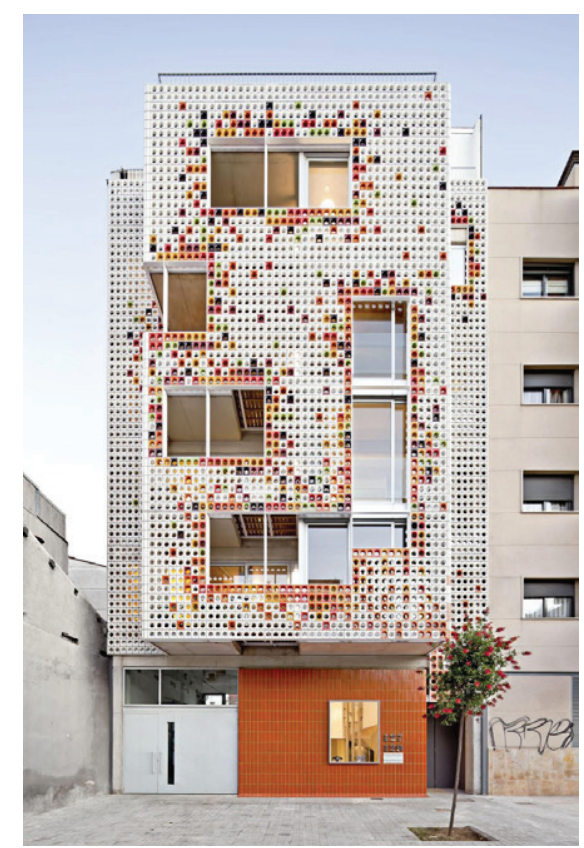

Figure 3. Family Housing in Bacholona (source: Multifamily Housing designed with a shiny colorful ceramic facade, 2016) 
which was designed by Lagula Arquitectes is one of the hundreds of buildings with colorful features which create identity and provide the live quality to such buildings.

\subsection{Natural light}

"Architecture is the masterly, correct and magnificent play of volumes brought together in light .... Le Corbusier, is emphasizing that "...the history of architecture is the history of the struggle for light" (LeCorbusier, n.d.) Natural light is a primary light source and in the past it was essential for people to do activities indoors. Now it became a means of implementing an energy efficiency strategy. At the beginning of $20^{\text {th }}$ century, advanced technology and infrastructure development made electric lighting affordable and safe. Since such changes took place during the last few decades, many common buildings are designed considering daylight as a primary indoor light source (Meek \& Wymelenberg, 2015). Daylight can be managed, controlled, and fine-tuned to our advantage to fulfil our daily life needs. There are unique ways to give life to architecture using natural light. Natural light is a living thing, and if we are attentive to this living force and use it creatively and serenely, we will be able to conceive spaces as light symphonies (Hobday, 2007). With the importance and significate of natural light for visual comfort achieved by providing adequate illumination levels for doing intended tasks, it must not affect the thermal comfort achieved by reducing the sun radiation inside the building. Most people appreciate day lighting and enjoy living in buildings. Figure 4 shows an interior view in Flatiron Duplex Loft, Manhattan, New York City which is designed by Shelton Mindel Associates Building which is well designed to provide the appropriate day lighting needed by human be-

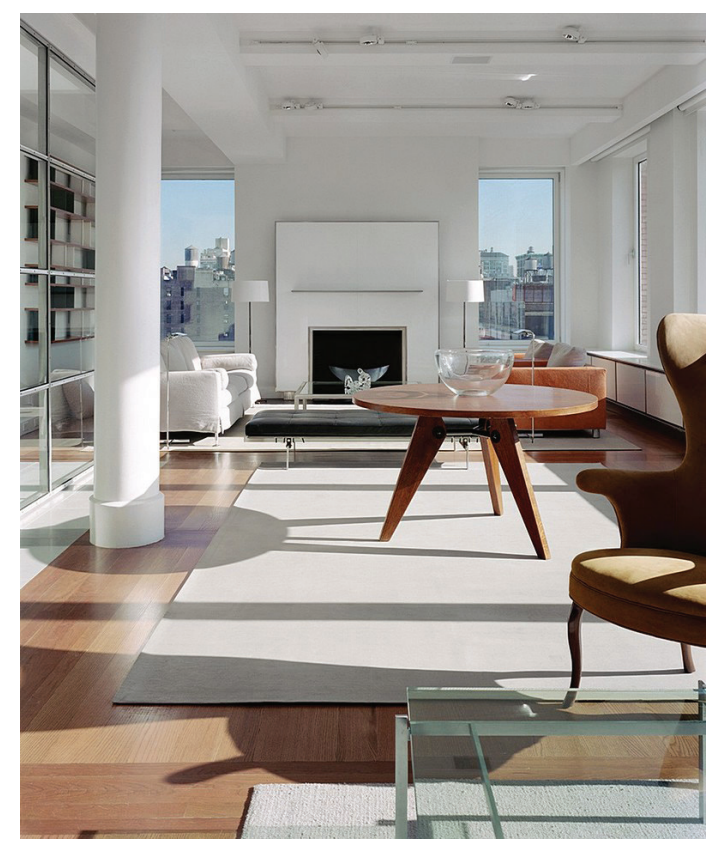

Figure 4. Interior view in Flatiron Duplex Loft, Manhattan, New York City (source: photo by Michale Moran Cited in (Love \& Grimley, 2007) and (Moran, 2017) ings which usually provides comforting, welcoming and great spiritual experience. There have been many studies about natural day lighting to observe its importance to human mind, mood, feelings etc. and its impact on life. We hear a lot in modern days about people having issues like depression, stress, etc. Studies have proven that natural day lighting has a direct relation to the improvement of human mentality, focus, productivity, mood, and the enhancement of human life quality. Architects must understand how to use space, form and light to make all these different factors work harmoniously to gather to give life to its occupiers. Today natural light can be considered as a medicine that stimulates the production of melanin, serotonin, dopamine and gamma-aminobutyric acids in human body enhancing impulse control, motivation, muscle coordination, calmness and focus. The main advantage of daylighting is to save energy but it does not mean that it is a matter of providing illumination to indoor spaces of a building. There are many equally significant aspects such as the changing nature of light to prevent its heat, composition of light spectrum and visual communication though the windows (Baker \& Steemers, 2013). A designer should consider strength of lighting according to the nature of the spaces. For instance, bright light is suitable for short but catastrophic? for long occupation (Bean, 2014). Therefore, Marc Fontoynont mentioned different considerations for different building types. For example, airports and railway terminals where wide range of activities under high stress needs high quality of lighting; bright light-colores affect the general atmosphere and produces uniform and spaces required for worship building (Fontoynont, 2013).

\subsection{Flexibility}

Flexibility of buildings ensure that the buildings work across its life. A flexible house is defined as housing that can adjust to changes of both social and technological needs such as expanding the users' numbers, or updating the old services. Moreover to adjust the changing demographical, economical, and environmental patterns such as household number, rental market and climatic changes respectively (Tatjana \& Jeremy, 2007). Architecture can be developed to have the ability to respond to the complex life changes and people's needs through time, as it promotes efficiency and sustainability. Space efficiency, climatic issues, privacy issues, light, ect., can be controlled and can be solved. Many buildings lack the ability to serve important functions which neither people nor architects thought would be needed by occupants, eg: the need for more rooms for the growing family, transformable rooms to serve different functions, extendable floors, walls, and balconies etc. A building can be designed with flexibility to provide users' needs through the changing season of the year and different functions. Movable walls allow the extension of indoor living to outdoor space either by connecting other spaces around such as a garden as shown in Figure 5. Austin house enables a flexible lifestyle, thus creating a larger living space. However, it can be closed 


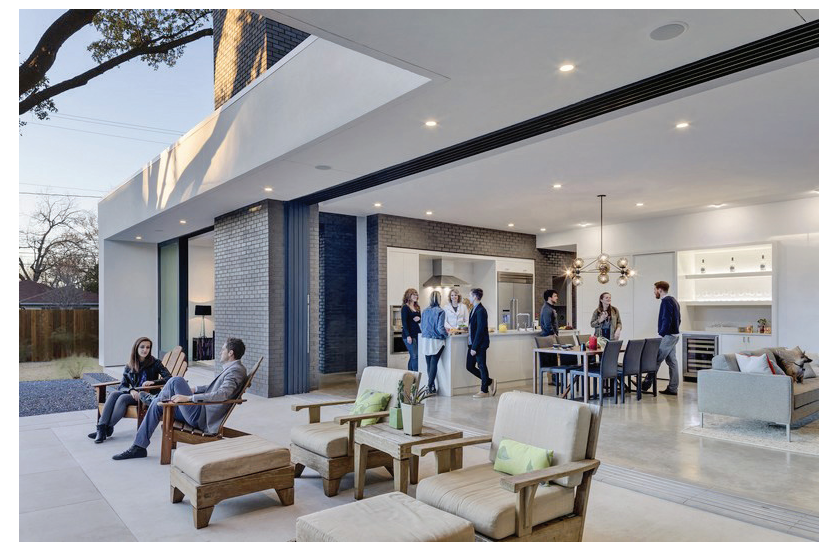

Figure 5. Austin House, USA (source: This Austin House enables a flexible lifestyle - Main Stay House by Matt Fajkus architecture, 2016)

to have the feeling of a normal house with full privacy and indoor quietness. Movable Walls are used indoors to extend a space when needed and to divide and separate a space into two spaces or more, creating a combination of spaces at any time needed. For example, dividing a kitchen area from a living room area, or dividing a guest room from a dining room, or creating a combination of rooms divided by movable walls then converted to a single room, etc. Using movable walls in a house or apartment can provide a variety of layouts and different uses of spaces and rooms. To design a building with movable walls, it is better to add the movable walls after being sure that the layout works well with non-movable walls. Flexibility provides success to architectural design that could be supported with philosophical and psychological evidences in which the people who use their buildings according to individual needs. They move furniture everywhere in spaces and add decorative features into walls, and color the windows with colored ribbon films (Kronenburg, 2015). This will clarify the added flexibility and spatial quality and functional variety to a building (Tatjana \& Jeremy, 2007).

\subsection{Shape and form}

Form refers to the externally recognized view of a building. A form is created by configuration and coordination of the building elements (Ching, 2007). Building shapes have been usually rigid in the early era. It was usually square or designed like a box which has a negative impact on human life. In Nature there isn't a thing around us that is square. However, there is a variety of perfect designs with a lot of attention to details. A building shape can be designed more dynamically and free form learnt from Nature in which it looks like a sculpture rather than just a building. An example is the Nanjing Zendi Himalayas Centre in China designed to resemble mountains with vertical louvres and shading windows that create the impression of streaming waterfalls.

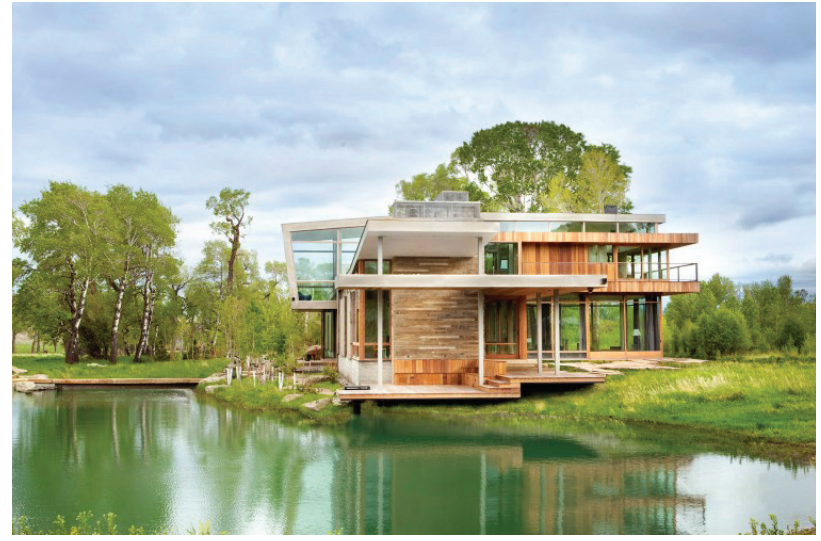

Figure 6. Big Timber Riverside House, Montana (source: Big Timber Riverside House - Montana ranch by Hughesumbanhowar architects, 2015)

\subsection{Water features}

Water is an important element for creating life in and around a built environment. Water is simple in Nature. It is a soft sculpture, flexible to be shaped to provide a unique design. The water, form, transparency, reflectivity, color, movement, and sound are qualities that make unique elements for design. A water feature has always been an important element in architecture. It was used for different purposes indoor and outdoor, as decoration to enhance the place visually with a good environmental quality, to cool the weather, and to be used as a swimming pool etc.

Where there is fresh and clean water, there will always be life around it. We feel comfortable and tranquil surrounded by water. We enjoy its noise when there is a waterfall or water jets nearby. It provides a welcoming environment. Water helps to turn our homes, buildings, cities and towns to something special, especially when integrated with landscape as shown in Figure 6.

\subsection{Multifunction}

Buildings are built to fulfil a certain function to satisfy people's needs. This determines the success of a building. However, buildings are made live by its people. People make buildings feel alive and active. One of the most active buildings today are the shopping malls. People enjoy going to shopping malls and families stay for a long time in shopping malls for entertainment. The reason is mainly the availability of outlets that satisfy the needs of people of all ages with a variety of products, food, Coffee shops, libraries, hangout areas, children's playing areas, etc. Malls like City Centre in Bahrain containing mixed-use spaces are very popular. Buildings that satisfy people's needs are more alive while buildings without people can be considered unused, Each function helps the other to be seen causing this liveness, which makes space live, if this movement stops, this space becomes useless. 


\subsection{Ornamentations and patterns}

Ornaments are architectural elements used in buildings exteriors and interior walls to enhance the beauty of buildings. Ornaments are very effective elements to give life to architecture as shown in Figure 7 and Figure 8. It is true that architectural beauty and excitement gives architecture a higher value. Ornaments reduce the rigidity of any building making it look more organic and composed. The more complex the ornamentation is, the more it is great and exciting. Complexity of ornaments must also has a certain amount of order to give joy and comfort. Ornaments are also expressive architectural elements making buildings into frozen stories speaking about their occupier's identity, and religious, economic and social values. Ornaments do not carry any loads in buildings; their function is decorative. There is a variety of ornament designs developed in architecture, on windows, walls, wall panels, ceilings, doors, windows etc. Gypsum, stone, wood, precious metals and plastic are used in modern ornaments. The more ornaments in buildings the more it gives the feeling of greatness and beauty. However, complexity of ornaments must have a certain amount of order to make it acceptable to human observation. Most modern buildings are of international style, and are about showing technological advancements, high speed construction, modern aluminum materials, and lack of ornaments which reduces its expression, artistic value and beauty. Ornaments were also used in historic civilizations to show the power of
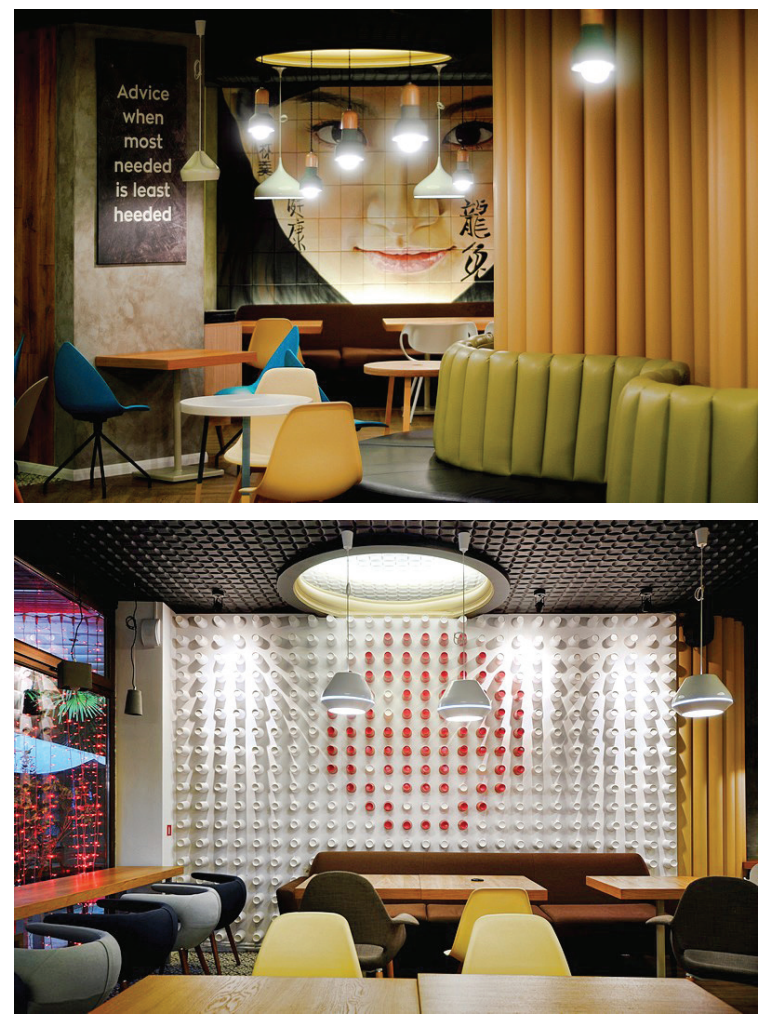

Figure 7. Interiors Patterns in Coffee Red Cup building, Krasnodar region, Russia Federation (source: Red Cup Sochi retro futuristic interior by Allarts Design, 2016)

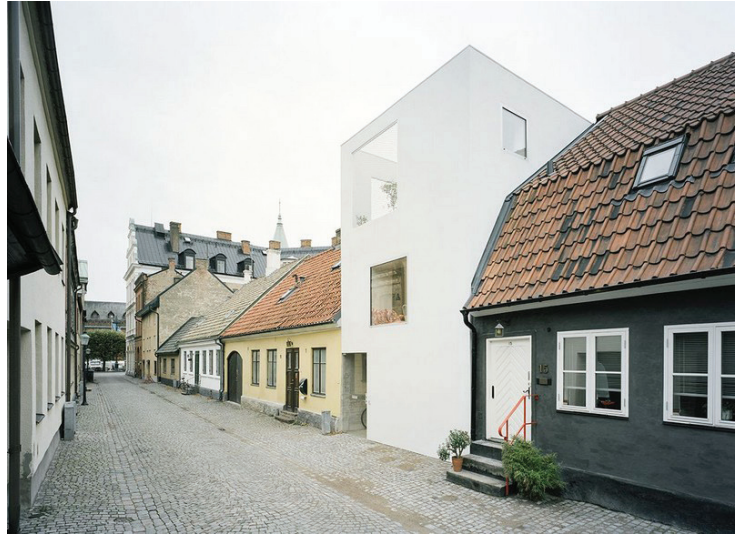

Figure 8. Exterior Pattern in Landskrona Townhouse, Sweden (source: Landskrona Townhouse - Swedish Contemporary Home by Elding Oscarson, 2016)

cities deterring enemies to wage wars against such powerful cities. Three types of ornaments exist; Mimetic ornament is the commonest type of architectural ornament, which can be found in traditional Asian and Western architecture. It is the rebuilding of ancient ornaments in to a more advanced technological materials and a more mature design. It is usually related to religious origins in which forms and shapes known to people and considered culturally valuable are reintroduced and reproduced in new forms and styles that can also be abstract or geometric patterns. The use of new materials like metal and glass as ornamental materials in the $19^{\text {th }}$ and $20^{\text {th }}$ century; applied ornament are ornaments that have no meaning or symbol other than decorative purposes. It is used to unify building structures and make them look more artistic and beautiful like the colosseums, where the set of columns were decorated forming a certain shape. Renaissance and Baroque Architecture depended on this concept; and Organic ornaments were reintroduced and formulated in the mid$20^{\text {th }}$ century. The main concept was to make ornaments a natural part of the building that emerges from a building design concept to serve its aesthetic function naturally from the building materials. For instance, Christian and Islamic medieval aesthetic period buildings were based on organic ornaments. Islamic ornaments, especially those borrowed from the meaningful words of the Quran were transformed to abstract ornament and Christian churches built with tangible symbols of heaven to give glorious impressions. The end result was to create an integration between Architectural forms, shapes, structures, materials and functions (Gowans, n.d.).

\section{Bahrain peoples' survey}

This survey was conducted in the form of a questionnaire survey administered to Bahrain people with the aim of identifying their evaluation of the building characteristics, which could produce alive architecture. The survey employed five scales to evaluate the effectiveness of ten building characteristics related to alive architecture. The survey 
was administered among all Bahrainis, residents and tourists in the Kingdom of Bahrain. The reason for selecting all the types of people in Bahrain was to ensure that the building characteristics were evaluated by people with different intentions. The survey was conducted employing a random sample of 308 respondents from all categories of people, having interest in the survey topic. It was widely published inviting volunteers to respond, and provide answers. It was intended to test the responses of different generations of respondents. Out of the total 308 respondents, $38 \%$ of the responses are female, $61 \%$ are male and $1 \%$ did not specify the gender. With regard to age, $42 \%$ respondents are below 21 years of age, $47 \%$ in the age of 31 to $35,8 \%$ above 35 and $3 \%$ didn't specify their age which shows that the data is representative including varied age groups and both the genders. The questionnaire consisted of five main parts; personal information as an optional aspect and ten questions about the degree of effectiveness of building characteristics to achieve alive architecture. The questionnaire was conducted online using google drive website application. 1000 invitations were sent to people living in Bahrain. 463 responded to the invitation by answering the questionnaire. To ensure validity of the questioned' answers, an image and brief discretion were attached to each question to illustrate the relevant building characteristic and architectural terms come in the question. In addition, all respondents' answers were assessed against bias and for not being serious. 53 respondents' answers were incomplete and 102 respondents' answers were biased; they did not contain a variety of choices of different questions (i.e. choice only the first/last option). A total of 155 respondents' answers were ignored. 308 respondents' answers represented all targeted categories of people as mentioned earlier.

\section{Results of Bahrain peoples' survey}

Considering the users opinion is a part of implementing a social design concept where the questioned peoples were enthusiastic to participate. The outcome data of the people survey has been analyzed as shown in Table 1; values in the table are number of respondents who select a significance degree of each building characteristic relevant to socio-alive building. The fewest respondents stated that all building characteristics has very weak significance. Highest percent of respondents stated that all building characteristics except space quality, ornaments and multifunction characteristics have strong significance. Whereas highest percent of respondents stated neutral significance to space quality ornaments and multifunction. There are variety of respondents' opinion regarding to very strong and weak significance. Therefore, overall scale of effectiveness of building characteristics has been calculated as a result submission of multiplying number of respondents in Table 2 by evaluation scale $(-2,-1,0,1$ and 2$)$ for each building characteristic. That calculation process outcome the scale

Table 1 . The survey results

\begin{tabular}{|c|c|c|c|c|c|c|c|c|c|c|c|}
\hline \multirow{2}{*}{ Questions: } & $\begin{array}{r}\text { Total Number of } \\
\text { respondents }\end{array}$ & \multicolumn{2}{|r|}{ Very Weak } & \multicolumn{2}{|r|}{ Weak } & \multicolumn{2}{|r|}{ Neutral } & \multicolumn{2}{|r|}{ Strong } & \multicolumn{2}{|c|}{ Very Strong } \\
\hline & Evaluation Scale & & -2 & & -1 & & 0 & & 1 & & 2 \\
\hline \multirow{8}{*}{ 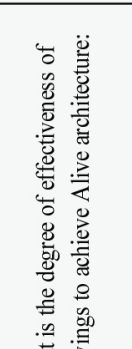 } & Space quality & 5 & 19 & 4 & 34 & 令 & 128 & $\$$ & 82 & 4 & 45 \\
\hline & \begin{tabular}{|l|} 
Proportions \\
\end{tabular} & $y$ & 12 & 4 & 37 & 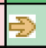 & 83 & 4 & 132 & 4 & 44 \\
\hline & Greenery & $y$ & 19 & $y$ & 37 & ดิ & 84 & ด & 99 & $\$$ & 69 \\
\hline & Colors & 5 & 14 & $y$ & 27 & $\$$ & 58 & 雨 & 121 & ए & 88 \\
\hline & \begin{tabular}{|l|} 
Natural light \\
\end{tabular} & $y$ & 20 & $\Rightarrow$ & 45 & $\Rightarrow$ & 58 & 过 & 94 & 过 & 91 \\
\hline & Flexibility & $y$ & 14 & 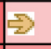 & 47 & $\Rightarrow$ & 66 & 4 & 94 & (4) & 87 \\
\hline & Shape \& Form & $y$ & 17 & $y$ & 36 & ๑ฺ & 77 & 4 & 95 & คิ & 83 \\
\hline & Water features & 5 & 16 & $y$ & 30 & คิ & 78 & 佥 & 108 & $\Rightarrow$ & 76 \\
\hline
\end{tabular}

Table 2. Overall scale of effectiveness of the building characteristics on alive architecture

\begin{tabular}{|c|c|c|c|c|c|c|c|}
\hline Characteristics & Very Weak & Weak & Neutral & Strong & Very Strong & Effectiveness & $\begin{array}{l}\text { Scale } \\
\text { Factor }\end{array}$ \\
\hline Space quality & & & & & & 100 & 5.8 \\
\hline Proportions & & & & & & 159 & 9.3 \\
\hline Greenery & & & & & & 162 & 9.5 \\
\hline Colors & & & & & 242 & 242 & 14.1 \\
\hline Natural light & & & & & & 191 & 11.1 \\
\hline Flexibility & & & & & & 193 & 11.3 \\
\hline Shape \& Form & & & & & & 191 & 11.1 \\
\hline Water features & & & & & & 198 & 11.6 \\
\hline Ornaments and Patterns & & & & & & 125 & 7.3 \\
\hline Multi-function buildings & & & & & & 153 & 8.9 \\
\hline
\end{tabular}

Note: ${ }^{*}$ - The evaluation scale is calculated by sum of multiplying number of respondents with its evaluation scale; ${ }^{* *}$ - The scale factor is calculated as percentage of each total points. 
Table 3. Classification of scale factors of building characteristics

\begin{tabular}{|c|c|c|c|}
\hline Characteristics & $\begin{array}{l}\text { Scale } \\
\text { Factor }\end{array}$ & $\begin{array}{c}\text { Natural } \\
\text { Break }\end{array}$ & Classification \\
\hline \multirow[t]{2}{*}{ Space quality } & 5.8 & & Low \\
\hline & & 1.5 & \\
\hline \multirow[t]{2}{*}{$\begin{array}{l}\text { Ornaments and } \\
\text { Patterns }\end{array}$} & 7.3 & & Slightly low \\
\hline & & 1.6 & \\
\hline \multirow[t]{2}{*}{$\begin{array}{l}\text { Multi-function } \\
\text { buildings }\end{array}$} & 8.9 & & \multirow{5}{*}{ Medium } \\
\hline & & 0.4 & \\
\hline \multirow[t]{2}{*}{ Proportions } & 9.3 & & \\
\hline & & 0.2 & \\
\hline \multirow[t]{2}{*}{ Greenery } & 9.5 & & \\
\hline & & 1.7 & \\
\hline \multirow[t]{2}{*}{ Natural light } & 11.1 & & \multirow{7}{*}{ Slightly high } \\
\hline & & 0.0 & \\
\hline \multirow[t]{2}{*}{ Shape \& Form } & 11.1 & & \\
\hline & & 0.1 & \\
\hline \multirow[t]{2}{*}{ Flexibility } & 11.3 & & \\
\hline & & 0.3 & \\
\hline \multirow[t]{2}{*}{ Water features } & 11.6 & & \\
\hline & & 2.6 & \\
\hline Colors & 14.1 & & High \\
\hline
\end{tabular}

factor of each building characteristic to achieve the socioalive properties. With natural break method of classification the numerical value, the building characteristics has been classified into five class which has low factor as space quality, slightly low factor as ornaments and patterns, Medium factor as Multifunction, proportions and greenery, slightly high as natural light, shape and form, flexibility and water feature, and high factor as colors. Table 3 shows the classification of these scale factors.

\section{Discussions}

1. Space: Space as an element of Socio-Alive Building received a mixed response from the survey population, $15 \%$ people of the survey felt that space is a very strong element for making architecture live; $27 \%$ felt strong and $41 \%$ expressed neutrality. $11 \%$ felt it weak and $6 \%$ very weak. $42 \%$ of the people considered space as strong and a very strong element for alive architecture. Furthermore $82 \%$ considered the space has certain significant because it supports the sociality feature of the buildings which can attract people to spend enjoyable time in a unique identity, artistic space. Overall evaluation of the space by the questioned people led to 5.8\% as scale factor of the space in crating alive-socio building, that low value might be affected by the high significance of other characteristics such as color, natural light, flexibility, shape and water feature.
2. Proportions: With regard to effectiveness of design proportions, $14 \%$ of respondents considered it very strong, $43 \%$ strong, $27 \%$ neutral, $12 \%$ weak and $4 \%$ very weak. Somehow, $57 \%$ considered that design plays a significant role in making architecture live. Even in this case, 27\% neutral response is slightly on the higher side. However proportions is important to art and aesthetics not the building's function, the overall evaluation of the proportions by the questioned people led to medium value (9.3\%) as scale factor of the proportions in creating alivesocio building, that indicate the average significance of the proportions for living mood of building that inspired from human factors as most existed living thing.

3. Greenery: as Dover stated in his book (Dover, 2015) the importance of indoor greenery led to increase in awareness of people about environment and greenery is also manifested in the results of our survey, $23 \%$ of the respondents felt that greenery plays a very strong role in making architecture live; $32 \%$ voted for strong, $27 \%$ for neutral, $12 \%$ weak and $6 \%$ very weak. Overall, $55 \%$ felt that greenery is important which indicates that people have to be made more aware about the importance of greenery not only for the building but also for the environment of the country in particular and the world in general. Overall evaluation of the greenery by the questioned people led to $9.5 \%$ as scale factor of the greenery in crating alive-socio building, that medium value indicate the peoples' awareness of green significant for social and economic benefits though reducing life-cycle costs, developing functional performance, encouraging social relationships at buildings communities and enhancing building image.

4. Color: Out of the total respondents, $29 \%$ felt that color plays a very strong role in making a building live; 39\% voted in favor of strong, $19 \%$ were neutral, $9 \%$ considered it weak and $4 \%$ as very weak. Overall, $58 \%$ voted in strong and very strong and a reduced percentage of neutral persons shows that people are more concerned about colors and understand its significance for human behavior, performance and comfort which support space social identity. Overall evaluation of the color by the questioned people led to $14.1 \%$ as scale factor of the color in crating alive-socio building, that very high value informs the significance of the color in the physiological comfort which support the sociality of the building. Furthermore that high value negatively affects the significance of some other characteristics such as space quality, ornaments and patterns.

5. Natural light: Surveyed population displayed greater awareness about importance of natural light and 30\% of the respondents voted Natural light as a very strong element, 30\% as strong, $19 \%$ were neutral, $15 \%$ weak and $6 \%$ as very weak i.e: approximately $60 \%$ of the respondents understood the significance of natural light in buildings and $40 \%$ were neutral or considered as weak. Overall evaluation of the natural lighting by the questioned people led to $11.1 \%$ as scale factor of the natural lighting in crating alive-socio building, that slightly high 
value indicates to the significance of the daylight for indoor which support the sustainability and enhancing the human mentality, focus, productivity, mood, visual comfort, health and of human life quality as well.

6. Flexibility: It does not come into play in day-to-day living and they become important only in case of specific situations and needs. Even then, 59\% of the respondents considered that design flexibility as strong and very strong $21 \%$ were neutral and $20 \%$ voted for weak and very weak category, indicating that $40 \%$ of the people did not consider flexibility in design as important. Overall evaluation of the flexibility of the design by the questioned people led to $11.3 \%$ as scale factor of the flexibility in crating alive-socio building, that slightly high value illustrates the significance of the flexible design which support the building sociality through encourage various social gatherings and activities, and keep the building alive though possibility of updating the old services and adjusting the demographical, economic and environmental pattern to face challenges to remain live.

7. Shape and Form: Mostly public at large associate shape and form with aesthetics that's why $27 \%$ of the respondents considered shape as an important element and voted for very strong category, $31 \%$ for strong, $25 \%$ neutral and $17 \%$ voted for weak and very weak category. Although $58 \%$ of the respondents understood the significance of shape, $42 \%$ did not consider shape as an important element. Generally, people are generally concerned about shapes of buildings. Overall evaluation of the building's shape and form by the questioned people led to $11.1 \%$ as scale factor of the shape and form in crating alive-socio building, that slightly high value of scale inform how far the shape and form are considered, especially the inspired from by the living things to give a live to the building.

8. Water Feature: In case of water, again $25 \%$ of responders were neutral indicating that they did not understand the significance of this natural element in making design more intimate. $25 \%$ considered this element as very strong, $35 \%$ voted in favor of strong, $25 \%$ were neutral and $15 \%$ voted it for weak and very weak. Water may not be as common an element as greenery but still has a very soothing and pleasing impact in the environment. Overall evaluation of the water feature in the building by the questioned people led to $11.6 \%$ as scale factor of in crating alive-socio building, that slightly high value of scale shows the awareness of responders about the role of water feature to enhance the place's environmental and visual properties and give the live to in and out door spaces.

9. Patterns and Ornamentation: Here again probably because lack of understanding, $34 \%$ respondents were neutral, $49 \%$ voted in favor of strong and very strong category while $17 \%$ considered this element as weak and very weak. The role of this element is little abstract hence the neutral category response was on the higher side. Overall evaluation of the patterns and ornamentation in the building by the questioned people led to $7.3 \%$ as scale factor in crating alive-socio building, that slightly low value of scale might come because of the people do not observe the details or they believe the ornaments is something traditional and old which already is existing in most of the mosques and traditional houses.

10. Multifunction: The mix use of the buildings is now considered a way of using the built space more intensely and making compatible activities cohabit the same building in a way to reduce traffic generation. But, $29 \%$ respondents were neutral and $20 \%$ voted in favor of weak and very weak category, 51\% respondents considered this element strong and very strong for making buildings more live. Mix use can be very useful in office areas, which become totally dead during night time. Overall evaluation of the multifunction for a building by the questioned people led to $8.9 \%$ as scale factor in crating alive-socio building, that medium of scale prove that multifunction characteristic has limited concern of the end-users, it might be a very significant to the owner to ensure attract mixture of activities to remain the building live.

\section{Case Study - Bahrain City Center}

It is located on northern government directorate of the Kingdom of Bahrain. It is the biggest shopping mall building in Bahrain, and it has 4 main entrances on the ground floor, 3 from the parking side and 1 from the road. On the first floor, there are 3 entrances from the multistory parking side, while 2 entrances in the second floor are also from the multistory parking. In total, there are 9 entrances to the building. The followings is an analysis of Socio-Alive Building characteristics of Bahrain City Center. The analysis is conducted based on the theoretical background and the observations by the authors. The outcome of the analysis would be integrated with the Bahrain Peoples' survey results to evaluate the building in term of live quality.

\subsection{Space}

Public spaces in the Bahrain City Center are mainly the circulation spaces, which are a set of long linear loops with different configurations in different floors. These long linear loops may have the disadvantage of not showing continuity. However, it raises the alive feature of the building by producing many different picnic paths with various characteristics in the same building. It also hides the corridors and shows the straight far ends. The spaces have been characterized according to the concept of specific / important and general. Where the plan in the center contains important and specific shops, and it gets more general as it gets away from the center. In the center of the city center shopping mall is the social area where people gather and activities take place, having double heights as it accommodates large amounts of people, giving the feeling of being in a big shopping mall. When activities take place, people from above ground levels gather around and enjoy watching the activities and having a great time while other people enjoy shopping due to the use of wide corridors, 


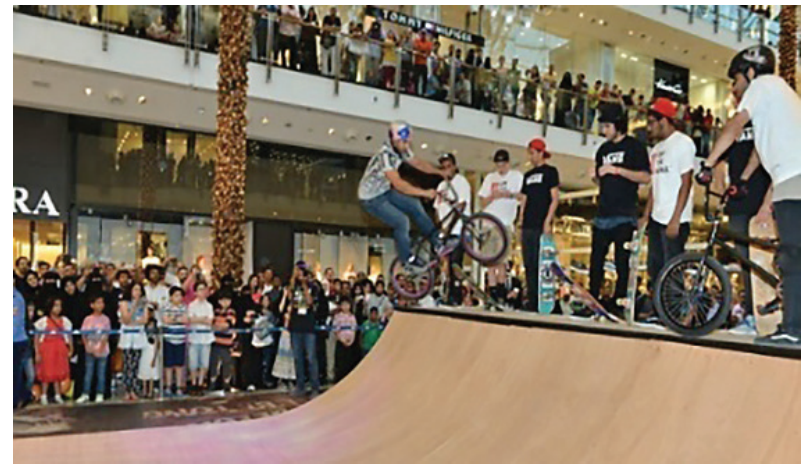

Figure 9. Double height inner space in Bahrain City Centre (source: captured by authors)

as shown in Figure 9. This kind of movement of people in space is a successful achievement of giving life to space, which can also be further improved and enhanced by finetuning different perspectives and dimensions. Therefore, the quality of spaces have successfully contributed to SocioAlive Building of the Bahrain City Center.

\subsection{Proportions}

It is observed that most façade composition parts is designed having the golden ratio as shown in Figure 10. This gives the building a more esthetic value to the façades and alive character of the building. Therefore, the building proportions have successfully contributed to Socio-Alive Building of the Bahrain City Center.

\subsection{Greenery}

The city center has been provided with few green elements, artificial palm trees in the social area and few other places in corridors as shown in Figure 11, which is not enough if
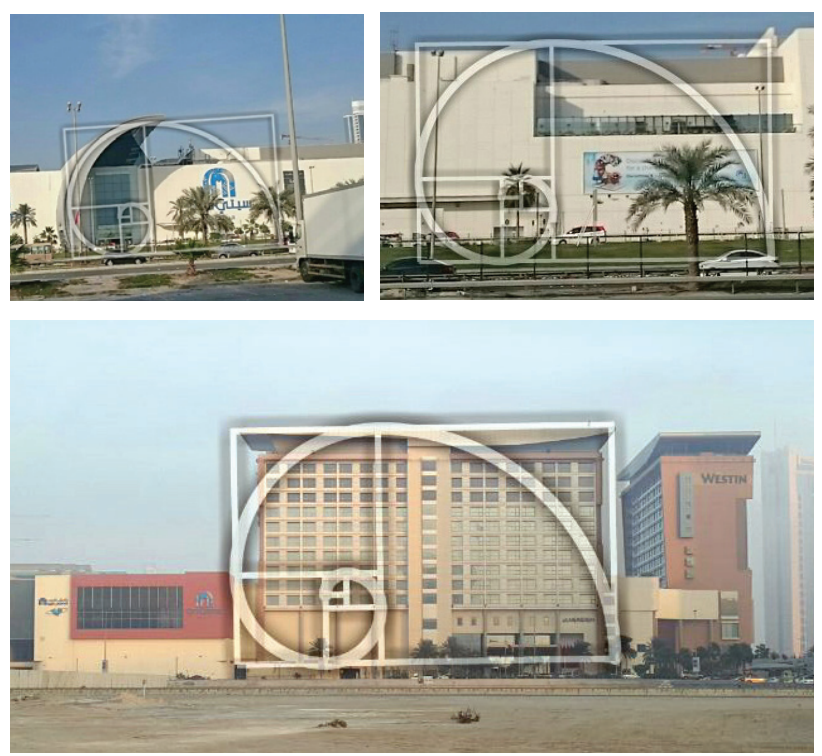

Figure 10. Golden ratio in Bahrain City Centre (source: captured by authors)

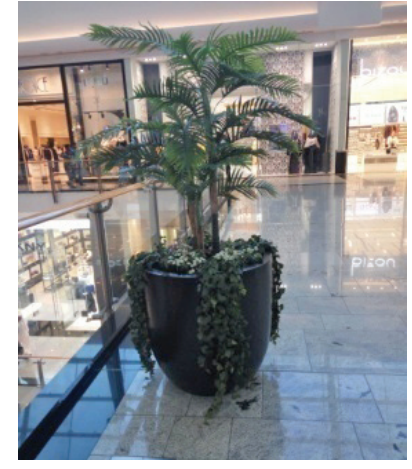

Figure 11. Greenery in Bahrain City Centre (source: captured by authors)

compared to human comfort. This might give the feeling of being in a very rigid building, which gives an uncomfortable feeling. The amount of trees and variety of needs to be provided in different ways must be spread inside the building, walls, and corridors. Therefore, the greenery has been unsuccessful in contributing to Socio-Alive Building of the Bahrain City Center.

\subsection{Color}

In the city center, colors have been used inside more than outside the building. Inside the building, as shown Figure 12 in the main central courtyard (Social Area) roof cool colors and warm colors have been used in a great and balanced manner, making it a perfect match for human comfort. However, in the vertical walls, white color dominates the interior making the building look bigger. Traditional café area near the mosque is colored with traditional mud like white, unusual to be found in a modern building creating a strong contrast; red color dominates the top walls and ceilings as shown Figure 13, allowing it to feel lower than its actual height and is therefore attractive. Most colors used inside the building is modern white, while the shops have glossy curtain walls (partition) to make it easier for shoppers to see the shop products. The floors as shown in Figure 14, are provided with glossy white marbles bordered by black marbles near the walls in the corridors and few decorations in the social court near the water feature. This mixture of simple colors and glossiness work well to gather to give an enjoyable feeling of new comfortable building for people. Therefore, the colors have successfully contributed to Socio-Alive Building of the Bahrain City Center.

\subsection{Natural light}

Natural light was considered in the city center design to provide natural light to enter the building during the daytime. However, this was limited to few areas in the building; most of it was concentrated on the center, social space, as well as the food court (NE), and few other skylight openings in the top of the corridors Figure 15. This lack of natural light could be due to the roof structure limitation or to decrease the air conditioning energy loss. The four courts in each end of the corridors Figure 16 


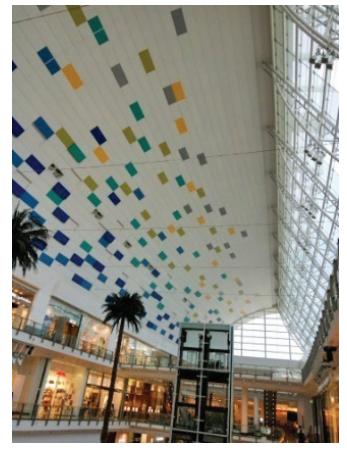

Figure 12. Colors in Bahrain City Centre (source: captured by authors)

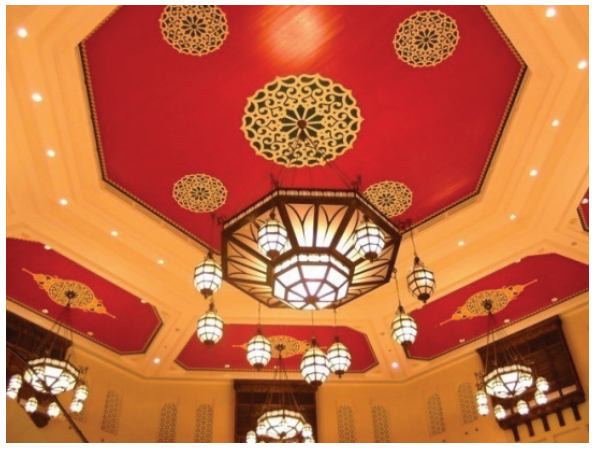

Figure 13. Colors in celling in Bahrain City Centre (source: captured by authors)

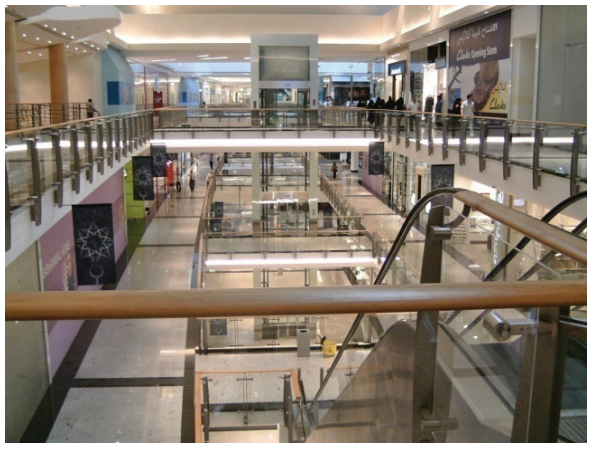

Figure 14. Floor in Bahrain City Centre (source: captured by authors)

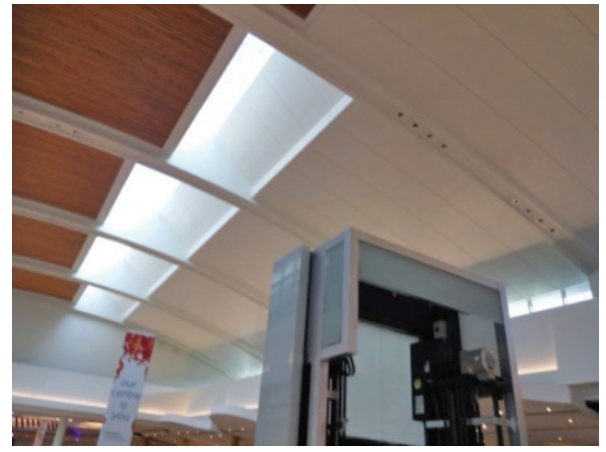

Figure 15. Skylight in corridors of Bahrain City Centre (source: captured by authors)
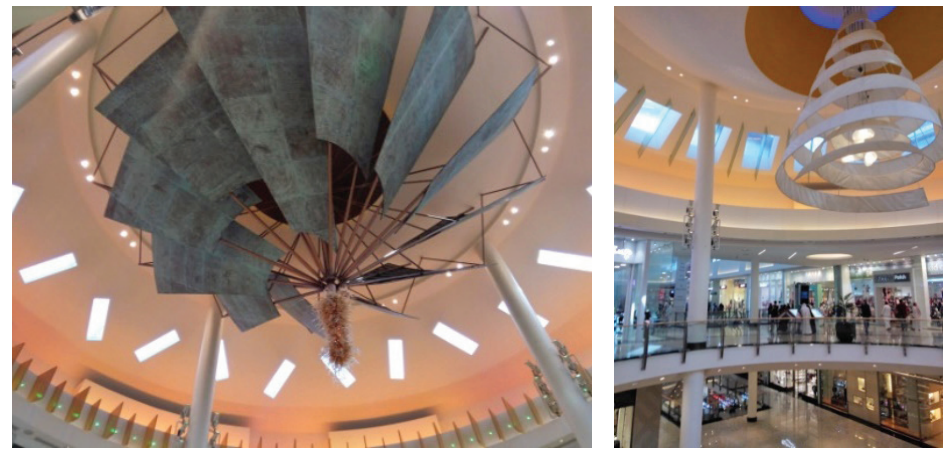

Figure 16. Skylight in courts of Bahrain City Centre (source: captured by authors) could have been better illuminated by skylight but may have been reduced for a certain reason. Therefore, natural light has a medium successful contribution on Socio-Alive Building of the Bahrain City Center.

\subsection{Flexibility}

Bahrain City centre has employed the concept of giving life to building by creating a flexible social space surrounded by organized spaces (shops). There different activities take place and people can enjoy and socialize, etc, the possibility of changing the space arrangement bringing life to space, while other people shopping comfortably or passing by and looking at activities from different floors and having a great time. On the other hand, flexibility in term of possibility for external extension is not existing in the Bahrain City Center due to many constrains. Therefore, flexibility has medium successful contribution on alive of the Bahrain City Center

\subsection{Shape and form}

The city center building was simply designed block shaped rigid. However to reduce its rigidity, some architectural elements have been added. Most noticeable was the curvature wall-roof composition extended from the ground to the roof outer walls sometimes recessed towards inside, and with different heights of roofs as well. Such forms suite the building's function. Therefore, the shape and form have successfully contributed to Socio-Alive Building of the Bahrain City Center.

\subsection{Water features}

Water features are available in one place in the city center building as shown in Figure 17. It is on the social area in the center where people gather. Unfortunately, it was provided within black marble which appears that the designer wanted to follow the color of the interior overall marble colors. However, blue color marble would've been more representative of pure water and give a better feeling of liveness. Therefore, the water features have inadequate successful contribution on Socio-Alive Building of the Bahrain City Center.

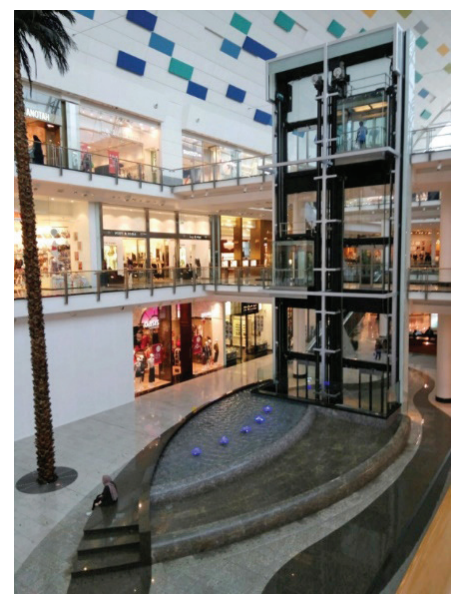

Figure 17. Few water feature in Bahrain City Centre (source: captured by authors) 
Table 4. Bahrain City Center Socio-Alive Building evaluation results

\begin{tabular}{|c|c|c|c|c|c|}
\hline Characteristics & $\begin{array}{c}\text { Effectiveness } \\
\text { Scale }\end{array}$ & Scale Factor & Designer Evaluation & $\begin{array}{l}\text { Designer Scale of } \\
\text { Successful }\end{array}$ & $\begin{array}{l}\text { Evaluation } \\
\text { Result }\end{array}$ \\
\hline Space quality & 100 & 5.8 & full successful & 100 & 5.8 \\
\hline Proportions & 159 & 9.3 & full successful & 100 & 9.3 \\
\hline Greenery & 162 & 9.5 & unsuccessful & 25 & 2.4 \\
\hline Colors & 242 & 14.1 & full successful & 100 & 14.1 \\
\hline Natural light & 191 & 11.1 & medium successful & 50 & 5.6 \\
\hline Flexibility & 193 & 11.3 & medium successful & 50 & 5.6 \\
\hline Shape \& Form & 191 & 11.1 & full successful & 100 & 11.1 \\
\hline Water features & 198 & 11.6 & inadequate successful & 75 & 8.7 \\
\hline Ornaments and Patterns & 125 & 7.3 & full successful & 100 & 7.3 \\
\hline Multi-function buildings & 153 & 8.9 & full successful & 100 & 8.9 \\
\hline \multicolumn{2}{|r|}{ Total } & 100 & & & 78.8 \\
\hline
\end{tabular}

\subsection{Multifunction}

The city center as a shopping mall is the best in Bahrain to date that provides a variety of and complex human needs such as shopping, eating, entertainment, exhibiting, advertising, seating and hospitality hotel. All such possible activities encourage a large number of Bahraini residents and tourists to spend a long time in the Bahrain City Center and provide always live quality to the building. Therefore, the multifunctional characteristic has successfully contributed to Socio-Alive Building of the Bahrain City Center.

\subsection{Ornamentations and patterns}

The city center is a modern shopping mall building and due to this, ornamentation is rare, except in the traditional section near the mosque where the top red color walls and roof contain an impressive and elegant ornamentation in different colors. Therefore, the ornaments and patterns have successfully contributed to Socio-Alive Building of the Bahrain City Center.

\section{Recommendations}

Architects in Bahrain are recommended to consider those building characteristics in order to produce socioalive buildings. The overall scale factors of the building characteristics could be considered as reference while assessing any building to identify its socio-alive prosperity. Architects researchers are recommended to conduct further and wider studies of building characteristic around the world taking into consideration this paper is an initiative to the socio-alive approach.

\section{Conclusions}

Although Socio-Alive is a very significant property of the buildings, it is a new subject and needs more research; this paper could be a good start. There are ten building characteristics that could bring live quality to the buildings which are quality of space, proportions, greenery, colors, natural lights, design flexibility, shape and form, water features, multi-functionality of the space, and ornaments and patterns. These characteristics have different significant scale factor; low factor as space quality, slightly low factor as ornaments and patterns, Medium factor as Multifunction, proportions and greenery, slightly high as natural light, shape and form, flexibility and water feature, and high factor as colors. Some of these characteristics support the sociality of the building such as space quality, flexibility, patterns and ornaments. Others support living of the building such as Proportions, natural lighting, shape, water feature and multifunction. In addition to greenery and color support both sociality and living of the building. The evaluation of Socio-Alive of Bahrain City Center is a combination analysis of authors as designers and Bahrain's people as end users. The designer evaluation mentioned earlier are converted to scale of success as $100 \%$ for full successful contribution, 75\% for inadequate successful contribution, 50\% for medium successful contribution, and $25 \%$ for un successful contribution. It has been done by multiplying scale factor of each Socio-Alive Building characteristic indicated by the users by and the authors' evaluation scale indicated by the designers. The evaluation results are listed in Table 4 Which demonstrates a lack of greenery, natural light, flexibility, and water feature roles in achieving live quality in the Bahrain City Center. On the other hand, there are six characteristics that add a great value of live quality to the building with a total of $78.8 \%$ of successful rating.

\section{References}

Al-Yaqoobi, L. H. (2013). Socio - architecture, a design approach for residential projects in Bahrain. Manama: Kingdom University.

Anthes, E. (2009). Building around the Mind. Scientific American Mind, 20, 52-59.

https://doi.org/10.1038/scientificamericanmind0409-52 
Baker, N., \& Steemers, K. (2013). Daylight design of buildings. New York, USA: Earthscan.

Bean, R. (2014). Lighting: interior and exterior (2nd ed.). New York, USA: Routledge. https://doi.org/10.4324/9781315857916

Big Timber Riverside House - Montana ranch by Hughesumbanhowar architects (2015, October 12). In Home World Design Architecture \& Design Magazin. Retrieved from http:// homeworlddesign.com/big-timber-riverside-house-montanaranch-by-hughesumbanhowar-architects/

Ching, F. D. (2007). Architecture: form, space, and order (3rd ed.). Hoboken, New Jercy: John Wiley \& Sons.

Dover, J. W. (2015). Green Infrastructure Incorporating plants and enhancing biodiversity in buildings and urban environments. New York: Routledge, Taylor \& Francis Group. https://doi.org/10.4324/9780203121993

Edwards, B. (2013). How do green buildings pay? In E. W. Brian, \& E. Naboni (Eds.), Green Buildings Pay Design, productivity and ecology (3rd ed., pp. 3-9). USA and Canada: Routledge. https://doi.org/10.4324/9780203082386

Ercan, M. A. (2010). Less public than before? Public space improvement in Newcastle city centre. In A. Madanipour (Ed.), Whose public space? International case studies in urban design and development (pp. 21-50). New York, USA: Routledge.

Fontoynont, M. (Ed.). (2013). Daylight performance of buildings. Lyon, France: Earthscan.

Gatsby, C. (2014, August 05). Social architecture: a new approach to designing social spaces. Retrieved from https:// www.huffingtonpost.com/claudia-gatsby/social-architecturea-new_b_5448130.html

Gowans, A. (n.d.). Applied ornament. Retrieved from http:// www.britannica.com/topic/architecture/Expression\#toc31854

Hobday, R. (2007). Light and life from the sun. In Daylight \& Architecture Magazine by VELUX(6) (pp. 8-16). VELUX Group.

Kenneth, A. G., \& Tammy, L. L. (2017). Green Gentrification Urban sustainability and the struggle for environmental justice. New York: Routledge from Taylor \& Francis Group.

Koch, D., Marcus, L., \& Steen, J. (2009). Architects are talking about space. In Proceedings of the 7th International Space Syntax Symposium (pp. 28:1-28-8). Stockholm.

Kronenburg, R. (2015). Flexible architecture: continuous and developing. In B. Kolarevic, \& V. Parlac (Eds.), Building dynamics: exploring architecture of change (pp. 30-42). New York: Routledge.

Kurtuncu, B., Koknar, S., \& Dursun, P. (2008). Decoding spatial knowledge and spatial experience. In Proceedings of Design Train Congress, 2. Amsterdam, The Netherlands.

Landskrona Townhouse - Swedish Contemporary Home by Elding Oscarson (2016, October 3). In Home World Design Architecture \& Design Magazin. Retrieved from http://homeworlddesign.com/landskrona-townhouse-swedish-contemporary-home/

LeCorbusier. (n.d.). AZQuotes.com. Retrieved from http://www. azquotes.com/quote/830312
Lefebvre, H. (1999). The production of space. Malden: Blackwell. Retrieved from http://mars1980.github.io/Space/resources/ Lefebvre-Production-of-Space-excerpts-1.pdf

Lehrer, J. (2011, April 14). The psychology of architecture. Retrieved from http://www.wired.com/2011/04/the-psychologyof-architecture/

Living building basics. (2017, August 05). Retrieved from https:// living-future.org/lbc/basics/\#overview

Love, M., \& Grimley, C. (2007). Color, space, and style: all the details interior designers need to know but can never find. USA: Rockport Publishers, Inc.

Meek, C., \& Wymelenberg, K. V. (2015). Daylighting and integrated lighting design. New York, USA: Routledge.

Moran, M. (2017, March 17). Flatiron Duplex Loft by Shelton Mindel \& associates. Retrieved from http://homeworlddesign. com/flatiron-duplex-loft-shelton-mindel/

Multifamily Housing designed with a shiny colorful ceramic facade. (2016, May 11). In Home World Design Architecture \& Design Magazin. Retrieved from http://homeworlddesign. com/multifamily-housing-designed-shiny-colorful-ceramicfacade/

Padovan, R. (2009). Proportion science, philosophy, architecture. London and New York: Routledge, Taylor \& Francis.

Pferdmenges, P. (2017, July 12). Alive architecture. Retrieved from http://www.alivearchitecture.eu/index.php/

Proshansky, H., Fabian, A., \& Kaminoff, R. (2014). Place-identity physical world socialization of the self. In J. J. Gieseking, W. Mangold, C. Katz, S. Low, \& S. Saegert (Eds.), The people, place, and space reader (pp. 44-81). New York: Routledge.

Red Cup Sochi - retro futuristic interior by Allarts Design. (2016, October 12). In Home World Design Architecture \& Design Magazin. Retrieved from http://homeworlddesign. com/red-cup-sochi-allartsdesign/

Ronchi, L. (2015). Lighting, color, environment and complexity: an abridged historical review. Firenze, Italia.

Shaftoe, H. (2008). Convivial urban spaces creating effective public places. UK: Taylor \& Francis.

Tatjana, S., \& Jeremy, T. (2007). Flexible housing. New York: Routledge.

This Austin House enables a flexible lifestyle - Main Stay House by Matt Fajkus architecture. (2016, June 16). In Home World Design Architecture \& Design Magazin. Retrieved from http:// homeworlddesign.com/austin-house-enables-flexible-lifestyle-main-stay-house/

TV House is made Up by different volumes centered around a green space by Bruno Vanbesien architects. (2016, April 24). In Home World Design Architecture \& Design Magazin. Retrieved from http://homeworlddesign.com/tv-house-is-madeup-by-different-volumes-centered-around-a-green-space/

Yerolymbos, Y. (2016, March 20). White walls transforms the city Silhouette of Nicosia. In Home World Design Architecture \& Design Magazin. Retrieved from http://homeworlddesign. com/white-walls-transforms-the-city-silhouette-of-nicosia/ 